\title{
Palm-based Oleochemicals in Non-Food Applications: Meeting the Environmental Regulatory Challenges
}

\author{
Razmah Ghazali*, Siti Afida Ishak and Noorazah Zolkarnain
}

\author{
Malaysian Palm Oil Board, 6, Persiaran Institusi, Bandar Baru Bangi, 43000 Kajang, Selangor, Malaysia
}

\begin{abstract}
The oleochemical manufacturing is one of the industrial sectors that contributed significantly to the economic growth of the country. Palm oil (PO) and palm kernel oil (PKO) have been utilised as feedstocks for production of the five basic oleochemicals, namely fatty acid, methyl ester, fatty alcohol, fatty amine and glycerol. These basic oleochemicals could be used without further treatment or they could be processed further for the purpose of purification and improving functionality, and then formulated with other ingredients into finished products. The industries, however, are challenged with the growing concern on safety, toxicity and eco-toxicity level, biodegradability profile and hence marketability of the products and new technologies developed. While Malaysian Palm Oil Board (MPOB)'s R \& D focused on developing various oleochemicals derivatives, the method to assess the environmental impact of the production of these products are also being looked into together with process feasibility and technology viability study. With a complete entity comprises of laboratories, facilities and expertise, MPOB can now assist Malaysian manufacturers/exporters to establish a complete dataset on biodegradation, ecotoxicity and life cycle assessment (LCA) to facilitate the market access of their products and ensure conformation to regulation set by importing countries.
\end{abstract}

Keywords: palm oil; renewable; oleochemical derivatives; OECD; REACh

\section{INTRODUCTION}

The Malaysian oil palm industry abides by several laws and regulations prevailing forest conservation, sustainability and environmental management. Among them are soil conservation, water management, biological pest control, and reduction of greenhouse gas (GHG) emissions and waste (Choo, 2012).

Regulations concerning environment are continuously getting more stringent while at the same time, the nonrenewable resources becoming depleted. These have open up opportunities for the oleochemicals to penetrate the market and substitute the petroleum-based products currently being used by consumers. Several drivers influence the huge growth of oleochemicals market including readily available raw materials, high demand from consumer markets and emerging market for green chemicals. The influence of oleochemicals development into various chemical products is becoming important due to the demand for bio-based products as well as sustainable solutions.

Oleochemical manufacturing sectors need to be innovative in order to remain competitive in the changing regulatory business. Advances in technology have created various new applications of oleochemicals in non-food sectors such as chemical block for polymers, base oil for lubricants and feedstock for bio-surfactant as well as conventional surfactant. From basic oleochemicals, i.e. fatty acid, fatty alcohol, fatty methyl ester, fatty amine and glycerine, further processing converts these basics into chemical intermediates with added functionality (Kushairi et al., 2018). The world oleochemicals market value in 2018 reached USD 19.10 billion. New development in applications together with product innovation and demand for biodegradable products will boost opportunities for oleochemicals businesses in bio- 
based industry over the forecast period 2019-2025 (Grandviewresearch, 2019).

New uses of oleochemicals have been established in numerous segments including bio-surfactants, biolubricants and bio-polymers, which offer significant longterm opportunities for manufacturing sectors. Chemical manufacturing companies are moving towards producing bio-based materials and ingredients, which contributed significantly to the major market growth of bio-based materials worldwide. In addition, financial incentives and tax benefits offered through government policies stimulated the growth of bio-based chemical industry. In Malaysia, direct and indirect tax incentives are provided for in the Income Tax Act 1967, Customs Act 1967, Sales Tax Act 1972, Excise Act 1976, Promotion of Investments Act 1986 and Free Zones Act 1990 (MIDA, 2019).

The evaluation of adverse effects of raw materials in consumer products in the environment is crucial in almost all industries. A product must satisfy stringent ecological criteria, in addition to good economic prospect and excellent performance, for it to be accepted worldwide. Numerous national and international laws have stipulated that, when a new chemical is to be registered, information on environmental impact has to be provided. Many new chemicals have recently been developed through dynamic R\&D efforts around the world and therefore, evaluation of the chemicals within the environmental perspectives is vital before they are to be commercialised and delivered to the consumers. Environmental data are required in order to fulfil various regulatory requirements set by the importing countries. One of them is known as Registration, Evaluation, Authorisation and Restriction of Chemicals, or REACh regulation. This single system substituted a number of European Regulations and Directives. Companies exporting chemicals into EU countries are required to register their products with the European Chemical Agency (ECHA).

\section{EU REACH AND OTHER REGULATIONS}

People around the world are eating food, taking medicines and using chemicals every single day. Therefore, the impacts of these products on health and environment are of concern to the public. Henceforth, manufacturers need to ensure the safety of their products at all stages, i.e. from production to final use, mandatorily consider all necessary legislative and safety requirements. The records of health and environmental impacts will fulfil not only a company's legal obligations, but also add value to its branding.

It is the responsibility of legal entity (also known as Only Representative) or EU importer based in the EU to register the chemical substances. The Malaysian oleochemical companies registered their basic oleochemicals with ECHA through the Only Representative and were involved in Substance Information Exchange Forum (SIEF). For registration purposes, manufacturers/exporters need to provide information to Only Representative or EU importers such as chemical safety report, safety and environmental assessment data, technical dossier, use conditions and exposure in different volume bands (MITI, 2015).

Many other countries require chemical substances to be registered by manufacturers and importers. The Korean chemicals regulation (K-REACh) has tonnage-based data requirements similar to the EU REACh Regulation. The regulation was introduced in 2013 with the first registration deadline ended in 2015. It is a staggered process over 10 years until 2023 (CIRS, 2012). All manufacture and import of new substances or existing substances above one tonne per year must be reported yearly. In addition, full registration before June 2018 was required for a list of 518 substances identified under the regulation. These must be registered jointly by the manufacture and importer of the same substance (DHI, 2017).

China also imposed REACh-like regulation for chemical substances since 2010, known as Provisions on Environmental Administration of New Chemical Substances. It applies to new substance either on its own, in preparation or articles intended to be released, and the one used as ingredients or intermediates. Companies must submit notification on new chemical substance, i.e., chemicals other than the approximately 45,000 substances currently listed in the Inventory of Existing Chemical Substances Produced or Imported in China (IECSC), to the Chemical Registration Centre of Ministry of Environmental Protection, irrespective of annual tonnage (DHI, 2017).

In Canada and US, notification on new chemical substances is in accordance with the New Substances Notification (NSN) Regulations (Chemicals and Polymers) 
and the US Toxic Substances Control Act (TSCA) section 12(b), respectively. Notification in the US requires collection of available toxicological information and use as basis for a registration dossier, though authorities may require additional information. Meanwhile, in Canada, notification requires evaluation of available toxicological and ecotoxicological data, and a fixed list of data requirements. Switzerland requires notification, registration and/or declaration of all new substances be done according to Swiss Ordinance on Protection against Dangerous Substances and Preparations (Chemicals Ordinance; ChemO, SR 813.11, 4th Revision) before placing them in the market, albeit they have been registered in the EU under REACh. Meanwhile, manufacturers or importers of chemicals in Russia need to conform to the requirements of the Russian Register of Potentially Hazardous Chemical and Biological Substances (Rospotrebnadzor). Notification involves submission of comprehensive ecotoxicological and toxicological information, which is decided and evaluated on a case-bycase basis by the Federal Services. The Russian legislation requires that the registration is renewed after a certain period, usually three years. Meanwhile, the Australian Chemicals Registration Scheme (NICNAS) requires manufacturer or importer of substances to include toxicological and ecotoxicological data in the registration dossier. The data requirement is tonnage dependent (DHI, 2017).

The Japanese Chemical Substances Control Law (CSCL) has been implemented since 1974, while the most recent amended law was published in 2009. Japan CSCL covers new and existing general industrial chemical products only. Agricultural chemicals, fertilisers, cosmetics, pharmaceuticals and food or feed additives are covered under different laws and acts. Prior to the manufacture or import of a new substance, manufacturers and importers in Japan must obtain approval notice from the government after submitting new chemical notification to three authorities: Ministry of the Environment (MOE), Ministry of Economy, Trade and Industry (METI) and Ministry of Health, Labour and Welfare (MHLW). This also applies to foreign manufacturers exporting new chemicals to Japan, where they have to submit new chemical notifications by themselves (CIRS, 2012).
In Malaysia, the chemical management regulation, i.e. "Environmentally Hazardous Substances Notification and Registration Scheme" (EHSNR), came into force in 2011 and the submission of environmentally hazardous substances data to the Department of Environment became mandatory. An environmentally hazardous substance (EHS) is a substance that is included in the EHS Reference List or a substance with Globally Harmonised System of Classification and Labelling (GHS) classification according to Malaysia GHS. The scope of this notification scheme exclude substances that have been notified/registered under other legislations such as the Pesticides Act 1974 (Act 149), Poisons Act 1952 (Act 366) and Chemical Weapons Convention Act 2005 (Act 641) (CIRS, 2016). Information provided by manufacturers to the Malaysian Government will enable the Department of Environment and other agencies involved in chemicals management to identify substances of concern and make decisions on how to safely manage the substances.

\section{OVERCOMING REGULATORY CHALLENGES}

Complying with legal and regulatory requirements is critical for any business and very pressing for industries with inherently high financial and reputational risks, such as the palm oil industry. This is even more pressing for palm oil companies operating in different jurisdictions that have varied regulatory approaches. Being aware of and maintaining compliance with emerging and existing requirements contained in the numerous applicable laws, regulations, standards and guidelines in any particular jurisdiction is of critical importance for timely progression of project activities, building long term relations with host governments and local communities, and maintaining the validity of granted permits and licenses. This is an everevolving task as host governments may revise and update the legislation applicable to the palm oil industry periodically, typically adopting stricter requirements rather than reducing the administrative and regulatory burden. Hence, achieving regulatory compliance can be seen as a moving target.

In all of the regulations discussed previously, companies are obliged to submit new chemical substance notification to 
the host government and information on environmental impact has to be provided. In order to meet the industry needs and satisfy regulation requirements of new products, the Advanced Oleochemical Technology Division (AOTD) of Malaysian Palm Oil Board (MPOB) has formulated a program on Environmental Assessment of Products, which is tailored into evaluation of the environmental performance via life cycle and ecotoxicological, i.e., biodegradation and ecotoxicity, assessments. The program has resulted in the formulation of R\&D activities and the establishment of Ecotoxicology Laboratories. These laboratories, which complied with the Organisation for Economic Cooperation and Development (OECD) Principles of Good Laboratory Practice (GLP), marked an important milestone to MPOB as their existence has helped industry in terms of generation of environmental impact data that are acceptable for product registration in most importing countries.

\section{ECOTOXICOLOGY ASSESSMENT}

Over the years, the urge to safeguard the environment from uncontrolled releases of pollutants has prompted the development of methods that can evaluate the adverse effects of substances. The environmental behaviour of new substances is normally evaluated based on two important parameters, i.e. biodegradation and ecotoxicity. These data are crucial and required for registration of products, preparation of safety datasheet, improving production process, etc. A number of standardised test methods have been established within the US (ASTM, 2011) and European Union (EU) (European Chemicals Bureau, 2010) to assess the effects and risks of substances in the environment. In addition, the methods help to evaluate linkages between period of exposure and severity of effects (European Chemicals Bureau, 2010). The OECD for example, has published a number of test guidelines for testing of chemicals, which are currently being applied by industries, governmental agencies and independent laboratories (OECD, 2011).

In order for the data to be accepted by EU countries, the tests must be conducted by OECD GLP-compliant test facilities. OECD GLP is a quality system related to the organisational conditions and process where studies on environmental safety and non-clinical health are planned, performed, monitored, recorded, archived and reported. The system ensures the generation of reliable and high quality test data. The principles of GLP are designed to harmonise testing procedures for the Mutual Acceptance of Data (MAD). Through MAD, test data generated according to OECD GLP in any member country shall be accepted in other member countries for various purposes, including assessment and practices related to the protection of human health and the environment. Malaysia is one of the non-EU countries that received full adherent status of MAD. Therefore, Malaysia will accept data from OECD countries and vice versa (OECD, 2017).

Thus far, 10 facilities in Malaysia have received OECDGLP compliance status from Standards Malaysia, where MPOB's Ecotoxicology Laboratories is one of them. Several tests adopted based on OECD test guidelines are offered to the industry (Table 1).

Table 1. List of ecotoxicology testing services in MPOB

\begin{tabular}{ccl}
\hline No. & \multicolumn{1}{c}{ Test } & \multicolumn{1}{c}{ Methods } \\
\hline 1 & Biodegradation & OECD 301 D, Closed Bottle \\
& & Test \\
& OECD 301 F, Manometric \\
& & Respirometry Test \\
& & OECD 201, Freshwater algae, \\
& Ecotoxicity & Growth Inhibition Test \\
& & OECD 203, Fish, Acute \\
& & Toxicity Test \\
\hline
\end{tabular}

\section{A. Ecotoxicology Assessment of Palm Methyl Ester Sulphonates (MES) as a Case Study}

There is an increase in environmental concern over the use of chemicals in large volume depending on their exposure period, persistence in the environment, and the behaviour of the affected organisms towards the chemical compounds (Cunningham \& Saigo, 1990).

A surfactant, a surface active chemical molecule, is widely used in almost all consumer and household products. Despite the widespread use of surfactant for various purposes, mainly in household cleaning products and commercial detergents, they can be potential toxicants when a large amount enters the environment. The foaming, eutrophication and reduction of oxygen transfer may pose 
environmental problems in the waterways to aquatic organisms (Hashim et al., 1992).

MES is an anionic surfactant derived from palm-based oleochemical feedstock and a technology to produce it is already well established worldwide (Zulina et al., 2017). It has good calcium tolerance, thus greater detergency and less sensitivity to water hardness than other anionic surfactants. Furthermore, it possesses attractive biological properties such as low toxicity and its biodegradability profiles are comparable to that of LAS.

According to Stratistics Market Research Consulting, the global MES market is accounted for \$790.36 million in 2017 and is expected to reach $\$ 2450.36$ million by 2026 , growing at a CAGR of $13.4 \%$ during the forecast period. Amongst application type, detergents segment is expected to remain attractive during the forecast period owing to enlarge in demand for domestic cleaning products including dishwashing and washing laundry. Some of the key players in global methyl ester sulfonate market are Wilmar International Ltd., Stephan Company, Cosmique Pvt. Ltd., Lion Corporation, K2 Industries, Guangzhou Keylink Chemical Co., Ltd, KLK OLEO, Guangzhou Lonkey Industrial Co Ltd., Sinopec Jinling Petrochemical Co.,Ltd, Chemithon Corporation, Emery Oleochemicals and Fenchem. (Reuters, 2019).

Japan is one of the countries that initiated the use of MES in detergents since early 1990s (Masuda et. al., 1994; Masuda, 1995). MPOB, conversely, has initiated several studies through this program to assess the environmental and cradle-to-gate performance of MES to promote its use in cleaning products.

Ecotoxicology assessment discussed here comprises of two components, i.e., biodegradation and ecotoxicity. Biodegradation is regarded as any process facilitated by living organisms that resulted in the alteration of a substance into organic and/or inorganic end-products, which are chemically different from the parent substance (Swisher, 1987; Larson et al., 1993). The tests for ready biodegradability, in which the pass levels of $60 \%$ carbon dioxide $\left(\mathrm{CO}_{2}\right)$ evolution, 60\% biological oxygen demand (BOD) or theoretical oxygen demand (ThOD), or 70\% dissolved organic carbon (DOC) removal within 28 days test period, have been developed as screening methods to resolve whether a substance can be easily biodegraded in the aquatic environment (OECD, 1992).

Razmah and Salmiah (2004) observed that MES was rapidly biodegraded in OECD 301D Closed Bottle Test during the first eight days (Figure 1) and achieved 60\% biodegradability, or the pass level, in just five days, thus confirming that it can readily biodegrades in the environment.

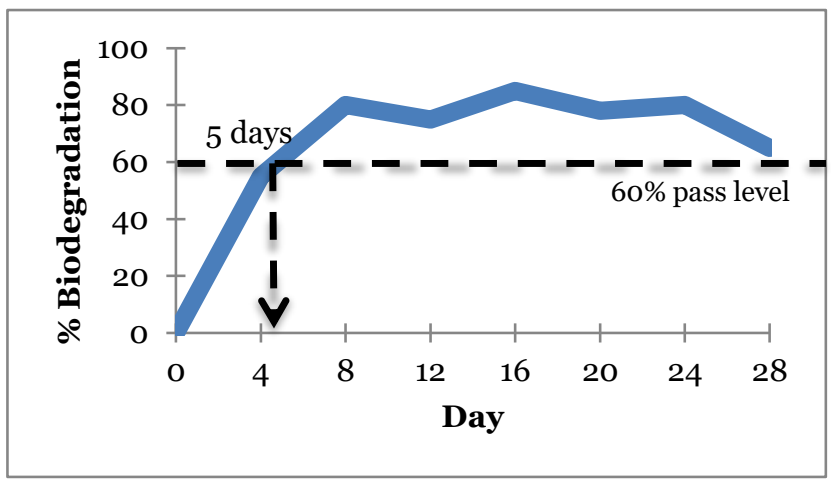

Figure 1. Biodegradation curve of MES in OECD 301D test

Later, Siti Afida et al. (2016) studied the potential of various homologues of $\mathrm{MES}, \mathrm{C}_{12}, \mathrm{C}_{14}$ and $\mathrm{C}_{16}$ carbon chain lengths, to be degraded in OECD 301F, Manometric Respirometry Test. Figure 2 shows that, relative to the biodegradability of reference material, aniline, which biodegraded to $60 \%$ in 3 days, the sequence of biodegradation for MES, from rapid to slow, was as follows: Aniline $>\mathrm{C}_{12} \mathrm{MES}>\mathrm{C}_{14} \mathrm{MES}>\mathrm{C}_{16}$ MES.

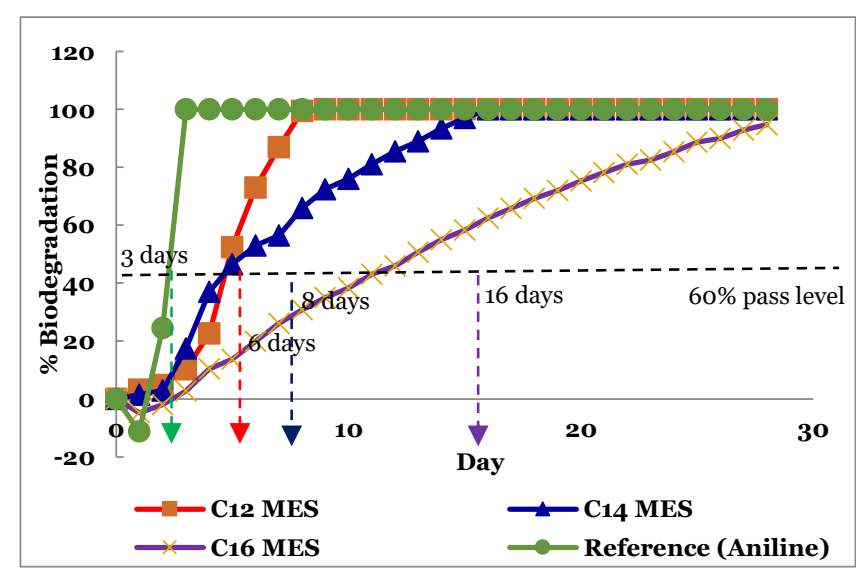

Figure 2. Biodegradation curves of MES and aniline in OECD $301 \mathrm{~F}$ method

It was justified that $\mathrm{C}_{12}, \mathrm{C}_{14}$ and $\mathrm{C}_{16}$ MES were readily biodegradable since $60 \%$ biodegradability was achieved 
within six days, eight days and 16 days, respectively, and can be considered as easily degraded in the environment. Linear-structured surfactants such as MES are easily degraded by the microbes compared to branched surfactants or surfactants with aromatic moiety. Furthermore, the solubility and biodegradability rate of MES decreases as its carbon chain length increases.

Another part of ecotoxicology assessment is ecotoxicity. Aquatic toxicity, or ecotoxicity, is the study of the effects of a material on aquatic organisms at various trophic levels, from subcellular through individual organisms to communities and ecosystems. It is evaluated through the reaction of the affected aquatic organisms to the material (APHA, 1980). Study on the ecotoxicity of surfactant is important since it is a component used in most household and consumer products, and is released into the environment via wastewaters (Hrenovic \& Ivankovic, 2007).

The ecotoxicity study of MES was performed using two different test organisms, i.e. green algae via OECD 201, Alga growth inhibition test and freshwater crustacean via OECD 202, Daphnia sp., Acute immobilisation test. For both OECD 201 and OECD 202 tests, the toxicity is evaluated through $\mathrm{EC}_{50}$-value $(\mathrm{EC}=$ effect concentration), i.e. the concentration that causes $50 \%$ reduction in growth of the green algae or immobility of $50 \%$ of $D$. magna within the test period.

After 72 hours of experiment, $\mathrm{C}_{12}$ and $\mathrm{C}_{14}$ MES showed $\mathrm{EC}_{50}$ value $>100 \mathrm{mg}$ litre $^{-1}$ towards green algae $(P$. subcapitata) (Table 2) and can be considered as practically non-toxic to this algae. It was observed that when the alkyl chain length of MES increases, the $\mathrm{EC}_{50}$ value decreases, meaning the toxicity increases. $\mathrm{C}_{16} \mathrm{MES}$, conversely, is poorly soluble in water, i.e. $10 \mathrm{mg}$ litre $^{-1}$ at test temperature, $24^{\circ} \mathrm{C}$. The toxicity test on poorly water-soluble substance should be conducted up to the maximum dissolved concentration under the test conditions (Weyman et al., 2012). Hence, the highest concentration tested was $10 \mathrm{mg}$ litre $^{-1}$ for $\mathrm{C}_{16}$ MES. At this concentration, only $7 \%$ of algae growth was inhibited. Since this concentration does not inhibited $50 \%$ of the algae growth, the $\mathrm{EC}_{50}$ value for $\mathrm{C}_{16}$ MES sample was $>10 \mathrm{mg}$ litre $^{-1}$ (Siti Afida et al., 2017).
The acute effect of $\mathrm{C}_{12}$ MES on D. magna was $>100 \mathrm{mg}$ litre $^{-1}$. As observed with green algae, the $\mathrm{EC}_{50}$ of MES decreases (became more toxic) with increasing carbon chain length of the surfactant (Table 2). This trend was also observed in many other anionic surfactants (Fendinger et. al., 1994; Razmah et al., 2016).

Table 2. Acute ecotoxicities of MES on P. subcapitata and Daphnia magna

\begin{tabular}{cccc}
\hline \multirow{2}{*}{ Result } & \multicolumn{3}{c}{ EC $_{50}\left(\mathbf{m g}\right.$ litre-1) $^{-1}$} \\
& MES & MES & MES \\
\hline $\begin{array}{c}\text { Pseudokirchneriella } \\
\text { subcapitata }\end{array}$ & $>100$ & $>100$ & $>10$ \\
Daphnia magna & $>100$ & 77.6 & 1.15 \\
\hline
\end{tabular}

Significant differences were observed in toxicity behaviour between structurally related palm-based MES irrespective of the test species. The toxicity increased as the hydrophobicity of the MES increased due to increase in alkyl chain length. According to Boeije et al. (2006), the ecotoxicity of surfactants normally increases logarithmically with a linear increase in alkyl chain length. As observed by other researchers (Schoberl et. al., 1988; Potokor, 1992; Fendinger et. al., 1994; Razmah et. al., 2016; Siti Afida et al., 2017), the possible reason for this is the larger interaction of the longer chain homologues with cell membranes (Ivankovic \& Hrenovic, 2010). However, the reliance of ecotoxicity on the alkyl chain length is only applicable for compounds that are fully soluble in water. This may be due to lower bioavailability of longer chain homologues, as they have lower solubility (Garcia et al., 2001).

Based on the Group of Experts on the Scientific Aspects of Marine Environmental Protection (GESAMP) rating scheme for acute aquatic toxicity (GESAMP, 2014), although palmbased MES seemed to be practically non-toxic $\left(\mathrm{EC}_{50}>100\right.$ mg litre-1), or slightly $\left(\mathrm{EC}_{50}>10-\leq 100 \mathrm{mg}\right.$ litre $\left.^{-1}\right)$ to moderately toxic $\left(\mathrm{EC}_{50}>1-\leq 10 \mathrm{mg}\right.$ litre $\left.{ }^{-1}\right)$ to aquatic organisms, depending on the test species and alkyl chain length of MES, their effects in the environment are harmless as only $10-30 \%$ of this surfactant is used in detergent products (Zulina et al., 2006), which is equivalent to other commercial surfactants. MES occurs mainly in the ionised form at environmental $\mathrm{pH}$ and as a result, it is anticipated 
that bioaccumulation is insignificant. In addition, dilution of MES in aquatic environment will contribute to its low local predicted environmental concentration (Razmah et al., 2006). In addition, risk assessment study conducted by Miura (2007) found that MES as 'low risk level' or of 'no concern' to the environment. The data on ecotoxicity effect of MES on freshwater organisms are useful and can be used to establish water quality criteria in a regulatory framework.

\section{LIFE CYCLE ASSESSMENT}

Besides biodegradation and ecotoxicity assessment, life cycle assessment (LCA) also needs to be established in order to overcome all the issues on sustainability and environment. LCA is an environmental management instrument for evaluating and improving the environmental quality of a production system over the whole life cycle. The impacts from a "life-cycle" or "cradle-to-grave" are evaluated at different stages starting from the withdrawal of raw materials; the processing and manufacturing of the product; the distribution or transportation of the product to the consumer; the application of product by the consumer; and the disposal or recycle of the product after its useful life. LCA has developed into a valuable decision-making tool for both policy makers and industry in assessing the cradle-tograve impacts of a product or process.

One can use a life cycle approach to address the issue of global warming, which is related to greenhouse gas (GHG) emissions. Malaysia perceives LCA as an investment to mitigate and ensure the sustainable production of palm oil and its products, as well as the competitiveness of sustainable palm oil in the global oils and fats market (Choo, 2012).

To-date, several LCA studies on production of basic oleochemicals and derivatives have been completed and some are still on-going, including study on palm-based polyol (Noorazah et al., 2015), methyl ester sulphonates (Noorazah et al., 2016), methyl ester (Noorazah et al., 2017), fatty acids and glycerol.

\section{A. LCA of Palm-based Methyl Ester Sulphonates (MES) as a Case Study}

An LCA study was conducted on palm-based MES production at pilot plant scale (Noorazah et al., 2016). The goal is to evaluate the possible environmental impacts from this production and also to find solutions or alternatives to reduce the impacts, where possible. The functional unit is set at 1 tonne of palm-based MES. The system boundary used was cradle-to-gate, from germination of oil palm seed up to production of MES. The SimaPro software version 8.0.2 with Eco-indicator 99 as methodology and Ecoinvent database was applied throughout the study.

The assessment showed that the most significant impact from the production originated from the production of methyl ester, steam, methanol and electricity (Figure 3). Production of methyl ester contributed the highest impact since the production and activities at the upstream level were included in the analysis, i.e. RBD palm stearin. This was followed by steam, where the impact was due to the utilisation of fossil material to produce steam. In this case, electricity was used to produce steam for the plant boiler. Since electricity itself is produced from non-renewable resources, it contributed the highest impact on fossil fuels impact category and is reflected through steam production. It can be concluded that the impact from steam was contributed by the production of electricity, and not from the steam consumption at the plant. The impact from wastes and emissions as output parameters from the production was small compared to the impact from the input parameters. The emission contributed by sulphur dioxide was only $0.02 \%$ from the total impacts generated during MES production.

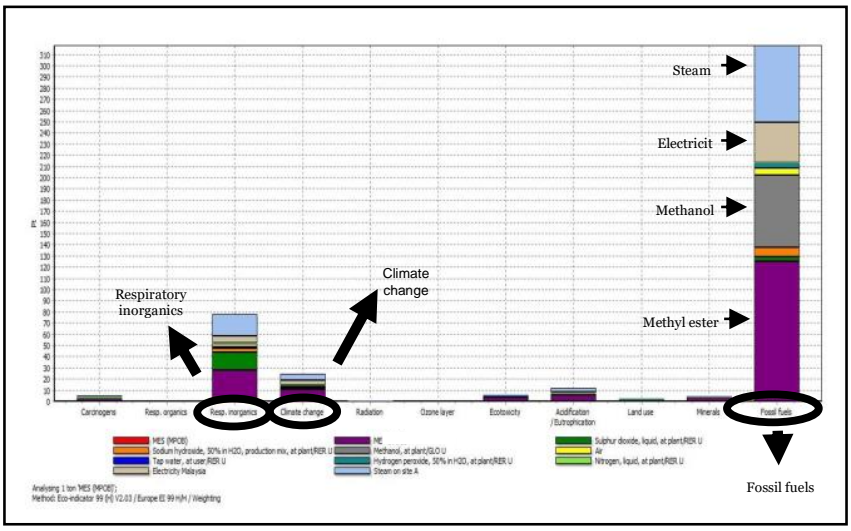

Figure 3. Life cycle impact assessment (LCIA) of 1 tonne of MES production 
Fossil fuels, respiratory inorganics and climate change were the most significant impact categories in MES production. The impact on fossil fuels category was contributed mainly by the production of methyl ester (used as feedstock to produce MES), steam, methanol and electricity. The highest impact on fossil fuels was due to the production of methyl ester where the impact mainly contributed from the upstream activities in order to produce the feedstock. The impact on respiratory inorganics category was mostly contributed by methyl ester and steam that were from the production of feedstock.

Michael et al. (2007) emphasised that resource and energy consumption, along with emissions, in the production of surfactant from palm oil were obviously more favourable than the one being produced from fossil feedstock. Therefore, palm-based MES can be the best alternative to replace petroleum-based surfactant in view of its environmental advantage and may assist the detergent industry to reduce the reliance on the fossil fuel resources.

\section{CONCLUSION}

Regulations are being amended to be more stringent than ever to suit the prime concern of the public on environmental safety in addition to the depletion of nonrenewable resources. This move has provided a greater prospect for the oleochemicals to claim bigger market share by substituting the conventional petroleum-based products. One of the drivers for the oleochemicals market is the increased demand from the end-use industries such as used to produce MES. The main air emissions generated was

personal care, soaps and detergents, lubricants, pharmaceuticals, and many others.

The rapid development of new palm-based chemicals and products has increased the demand for environmental assessments to ensure their acceptability and safe use to human and environment. The data are also required by the regulating authority, especially in Europe, to ensure the industry conform to the requirement of the regulation. One potential palm-based chemical is MES that has been applied as the primary surfactant in powder and liquid laundry detergents as well as in dishwashing liquids. A complete dataset on biodegradation, ecotoxicity and life cycle assessment (LCA) has been established to facilitate its market access and ensure conformation to regulation. With the availability of a complete entity comprises of laboratories that comply with OECD principles of GLP, world-class facilities and expertise, MPOB has now become a one-stop centre to deliver a complete assessment data to address environmental issues related to palm oil and oleochemical products, thus supporting the industry to meet the challenges of global regulation.

\section{ACKNOWLEDGEMENT}

The authors wish to thank the Director-General of MPOB for permission to publish this paper. Thanks are also extended to members of the Environmental Product Assessment group for their technical assistance and also to Ms Zulina Abdul Maurad for supplying the MES samples.

substance-specific toxicity predictions', Ecotoxicol. Environ. Saf., vol. 4, pp. 75-84.

Choo, YM 2012, Malaysia: Economic transformation ASTM 2011, American Society for Testing and Materials, $\begin{array}{llll}\text { viewed } & 17 & \text { October }\end{array}$ <http://www.astm.org/Standard/index.shtml >.

Boeije, GM, Cano, ML, Marshall, S, Belanger, SE, Van Compernolle, R, Dorn, PB, Gümbel, H, Toy, R \& Wind, T 2006, 'Ecotoxicity quantitative structure-activity relationships for alcohol ethoxylate mixtures based on advances oil palm industry, viewed 29 May 2019, <https://www.aocs.org/stay-informed/informmagazine/featured-articles/malaysia-economictransformation-advances-oil-palm-industry-september2012>.

CIRS (Chemical Inspection and Regulation Service) 2012, viewed 17 October 2017, <http://www.cirs- 
reach.com/KoreaTCCA/Korea_REACH_The_Act_on_the Registration and Evaluation of Chemicals.html>.

CIRS (Chemical Inspection and Regulation Service) 2016, viewed 29 May 2019, <http://www.cirs-reach.com/newsand-articles/malaysia-environmentally-hazardoussubstances-notification-and-registration-schemeehsnr.html>.

Cunningham, PC \& Saigo, BW 1990, Environmental science, a global concern. Wm. C. Brown Publishers, US.

DHI 2017, REACH and global chemicals registration, viewed 10 October 2017, <https://www.dhigroup.com/areas-ofexpertise/product-safety-and-environmental-risk $>$.

European Chemicals Bureau 2010, viewed 18 June 2017, <http://tcsweb3.jrc.it/testing-methods/>.

Fendinger, NJ 1994, 'Environmental behaviour and fate of anionic surfactants', in Environmental Chemistry of Lakes and Reservoirs (Baker, L A ed.), American Chemical Society, Washington, pp. 528-557.

Garcia, MT, Ribosa, I, Guindulain, T, Sanchez-Leal, J \& Andvives-Rego, J 2001, 'Fate and effect of monoalkyl quaternary ammonium surfactants in the aquatic environment', Environ. Pollut., vol. 111, pp. 169-75.

GESAMP 2014, Revised GESAMP Hazard evaluation procedure for chemical substances carried by ships. 2nd ed. London: International Maritime Organization, pp. 32.

Grandviewresearch 2019, Oleochemicals market size, share and trend analysis report by product (fatty acid, fatty alcohol, glycerol), by region and segment forecasts, 2019 2025, viewed $30 \quad$ May 2019, $<$ https://www.grandviewresearch.com/industryanalysis/oleochemicals-industry $>$.

Hashim, MA, Kulandai, J \& Hassan, RS 1992, 'Biodegradability of branched alkylbenzene sulphonates', J. Chem. Tech. Biotechnol., vol. 54, pp. 207-214.

Hrenovic, J \& Ivankovic, T 2007, 'Toxicity of anionic and cationic surfactant to Acinetobacter junii in pure culture', Central European J. Biology, vol. 2, no. 3, pp. 405-414.

Ivankovic, $\mathrm{T} \&$ \& Hrenovic, $\mathrm{J}$ 2010, 'Surfactants in the environment', ArhHigRada Toksikol, vol. 61, pp. 95-110.

Kushairi, A, Loh, S K, Azman, I, Elina, H, Ong-Abdullah, M, Zanal Bidin, M N I, Razmah, G, Sundram, S \& Parveez, GKA 2018, 'Oil palm economic performance in Malaysia and R\&D progress in 2017', J. Oil Palm Res., vol. 30, no. 2, pp. 163-195.

Larson, R, Rothgeb, T, Shimp, R, Ward, T \& Ventullo, R 1993, 'Kinetics and practical significance of biodegradation of linear alkylbenzene sulfonate in the environment', J. Am. Oil Chem. Soc., vol. 70, no. 7, pp. 645-657.

Masuda, M, Odake, H, Miura, K \& Oba, K 1994, 'Effects of 2sulphonatofatty acid methyl ester ( $\alpha$-SFME) on aquatic organisms and activated sludge', J. Jpn. Oil Chem. Soc. (YUKAGAKU), vol. 43, no. 7, pp. 551-555.

Masuda, M 1995, 'Environmental aspects of detergent materials - biodegradation of detergent surfactants', Proceeding of the 21st World Congress of the International Society for Fat Research (ISF), PJ Barnes and Associates, vol. 3, pp. 649- 653 .

Michael, ARM, Jürgen, OM \& Ulrich, SS 2007, 'Plant oil renewable resources as green alternatives in polymer science', Chemical Society Reviews, vol. 36, pp. 1788-1802.

MIDA 2019, Incentives in manufacturing sector, viewed 12 September

2019,

$<$ https://www.mida.gov.my/home/incentives-in-

manufacturing-sector/posts/>.

MITI 2015, Complying with EU-REACh: What industries should know and do, viewed 19 February 2017, <https://www.miti.gov.my/index.php/pages/view/516>.

Miura, K 2007, 'Aquatic risk assessment of 2-sulfonato fatty acid methyl ester sodium salt (MES)', J. Oleo Sci., vol. 56, pp. 123-128.

Noorazah, Z, Sumiani, Y, Vijaya, S, Zulina, A M, Zailan, A B, Razmah, G \& Hazimah, AH 2015, 'Evaluation of environmental impacts and GHG of palm polyol production using life cycle assessment approach', J. Oil Palm Res., vol. 27, no. 2, pp. 144-155.

Noorazah Zolkarnain, Zulina Abd Maurad, Razmah Ghazali \& Hazimah Abu Hassan 2016, 'Environmental performance of palm-based methyl ester sulphonates production using life cycle approach', J. Oil Palm Res., vol. 28, no. 1, pp. 104-113.

Noorazah Zolkarnain, Zulina Abd Maurad, Razmah Ghazali \& Zainab Idris 2017, 'Environmental assessment on methyl ester production from palm feedstock: A case study', J. Oil Palm Res., vol. 29, no. 3, pp. 412-421.

OECD 1992, OECD guidelines for the testing of chemicals.

Section 3: Degradation and accumulation. Test 301: Ready biodegradability. OECD, Paris, France.

OECD 2011, Organisation for Economic Cooperation and Development, viewed 20 January 2011, $<$ http://www.oecd.org/home>. 
OECD 2017, Non-member adherents to the OECD system for mutual acceptance of chemical safety data, viewed 10 October 2017, <http://www.oecd.org/env/ehs/nonmember-adherens-to-oecd-system-for-mutualacceptance-of-chemical-safety-data.htm>.

Potokor, MS 1992, 'Acute, subacute and chronic toxicity data on anionics' in Anionic Surfactants, Biochemistry, Dermatology (Gloxhuber, $\mathrm{C}$ and Kunstler, K eds.). 2nd edn, Surfactant Science Series, vol. 43, pp. 81-116.

Razmah, G \& Salmiah, A 2004, 'Biodegradability and ecotoxicity of palm stearin-based methyl ester sulphonates', J. Oil Palm Res., vol. 16, pp. 39-44.

Razmah Ghazali, Zulina Abd Maurad, Parthiban Siwayanan, Mohtar Yusof \& Salmiah Ahmad 2006, 'Assessment of aquatic effects of palm-based alpha-sulphonated methyl ester (SME)', J. Oil Palm Res., vol. 18, pp. 225-230.

Razmah Ghazali, Siti Afida Ishak, Zulina Abd Maurad, Noorazah Zolkarnain \& Hazimah Abu Hassan 2016, 'A comparative study of acute ecotoxicity of palm-based methyl ester sulphonates (MES) to Tilapia nilotica and Daphnia magna', J. Oil Palm Res., vol. 28, no. 3, pp. 234239.

Reuters 2019, Methyl ester sulfonate: Market size, share, report, analysis, trends \& forecast to 2026, viewed 12 November 2019,

$<$ https://www.reuters.com/brandfeatures/venturecapital/article?id $=97645>$.

Siti Afida, I, Razmah, G \& Zulina, A M 2016, 'Biodegradation of various homologues of palm-based methyl ester sulphonates (MES)', Sains Malaysiana, vol. 45, no. 6, pp. 951-956.

Siti Afida Ishak, Razmah Ghazali, Zulina Abd Maurad \& Noorazah Zolkarnain 2017, 'Ecotoxicology study of various homologues of methyl ester sulfonates (MES) derived from palm oil', J. Surfactants Deterg., vol. 20, no. 6, pp. 1467-1473. doi: 10.1007/s11743-017-2011-3.

Schoberl, P, Bock, KJ, Marl \& Huber, L 1988, 'Data relevant to the ecology of surfactants in detergents and cleaning agents', Report on the state of discussion in the studygroups Degradation/Elimination and Bio-Testing of the Main Committee Detergents. Copyright of Carl Hanser Verlag, Munich.

Swisher, RD 1987, Surfactant Biodegradation. Surfactant Science Series, 2nd edn, Marcel Dekker Inc., New York. pp. 1-1087.

Weyman, GS, Rufli, H, Weltje, L, Salinas, ER \& Hamitou, M 2012, 'Aquatic toxicity tests with substances that are poorly soluble in water and consequences for environmental risk assessment', Environ. Toxicol. Chem., vol. 31, no. 7, pp. 1662-1669. doi: 10.1002/etc.1856.

Zulina Abd Maurad, Razmah Ghazali, Parthiban Siwayanan, Zahariah Ismail \& Salmiah Ahmad 2006, 'Alphasulphonated methyl ester as an active ingredient in palmbased powder detergents', J. Surfactants Deterg., vol. 9, no. 2, pp. 161-167.

Zulina Abd Maurad, Zainab Idris \& Razmah Ghazali 2017, 'Performance of palm-based C16/18 methyl ester sulphonate (MES) in liquid detergent formulation', J.Oleo Science, 66(7), pp. 677-687. doi: 10.5650/jos.ess16190. 